\title{
LASER SPECTROSCOPY AND MASS MEASUREMENTS ON ALKALI ISOTOPES
}

\author{
C. THIBAULT \\ Laboratoire René Bernas du C.S.N.S.M., F-91406 Orsay, France
}

\begin{abstract}
Isotope shifts, spins, hyperfine structures and masses have been measured for the series of the alkali isotopes including the nuclei far from stability. The method of laser spectroscopy and its combinations with rf excitation are described. Some results are discussed, namely the first observation of the red doublet $D_{1}-D_{2}$ of francium, and the study of shell effects and changes of shape with mass and $\delta\left\langle r^{2}\right\rangle$ measurements for $\mathrm{Rb}$ and $\mathrm{Na}$ isotopes.
\end{abstract}

\section{Introduction}

The aim of the experiments which are described here was to study the groundstate properties of the nucleus as a function of the neutron number. Up to now, these experiments were conducted on the series of alkali isotopes since they are particularly suitable for laser spectroscopy as well as for mass measurements. As shown in fig. 1, we have studied the shell effects $(N=20,28,50,82,126)$, the odd-even staggerings, the shape isomerisms and the occurrence of deformations. We have tried to measure as many properties as possible concerning the same nuclei in order to obtain cross information.

On one hand, we measured the spin $I$, the magnetic moment $\mu$, the spectroscopic electric quadrupole moment $Q_{s}$, and the variation of the mean square charge radius $\delta\left\langle r^{2}\right\rangle$ by on-line laser spectroscopy eventually combined with a radio frequency excitation, and on the other, we measured the masses $M$ by on-line mass spectrometry.

The nuclei far from stability have been produced using three different kinds of nuclear reactions: the spallation, the fission and the fragmentation by high-energy protons (see fig. 1). These experiments were performed either at ISOLDE, which is a mass separator on line with the S.C. (600 MeV protons) at CERN, or directly on line with the P.S. (10-20 GeV protons) at CERN. A typical example of available yields is given in fig. 2.

In the following sections, the method of laser spectroscopy will be explained in detail, and the special case of francium will be discussed, also in detail. Some in- 


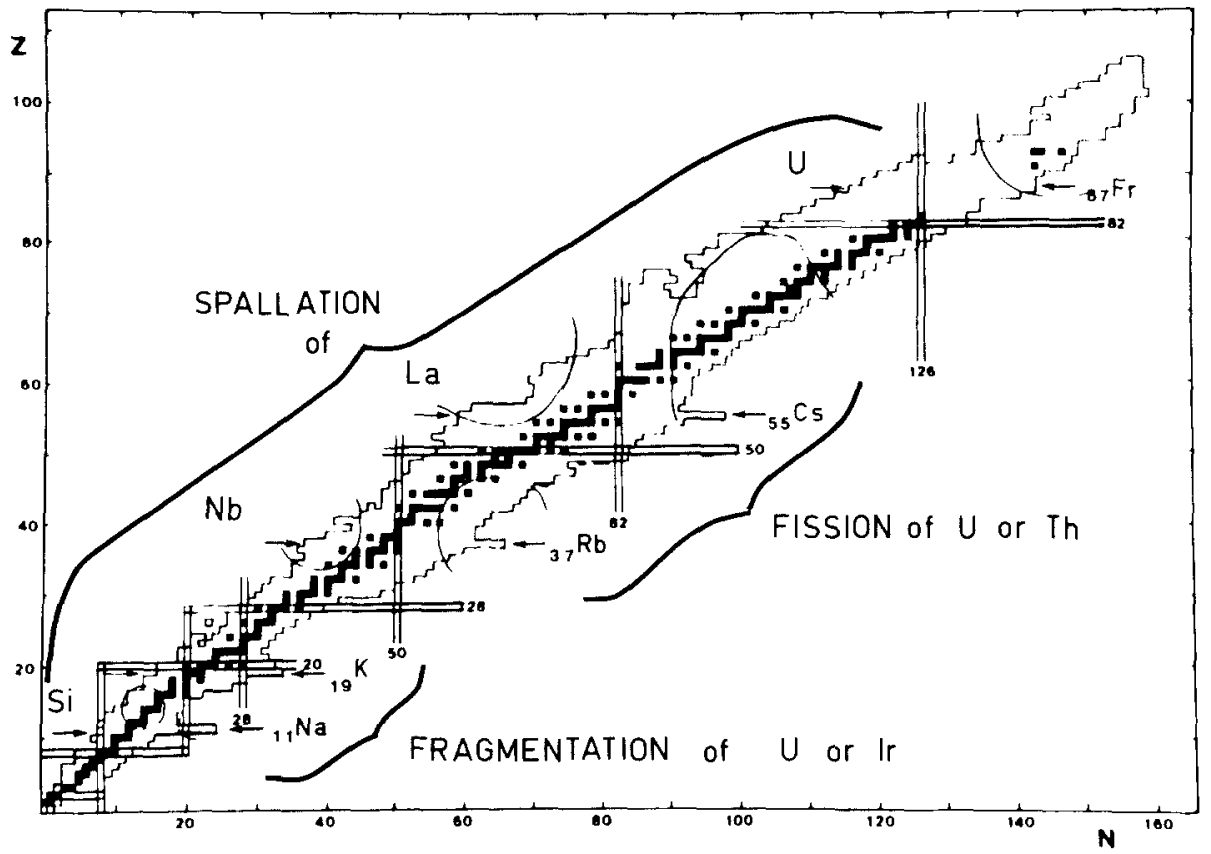

Fig. 1. Chart of the nuclides indicating the studied isotopes and their production modes.

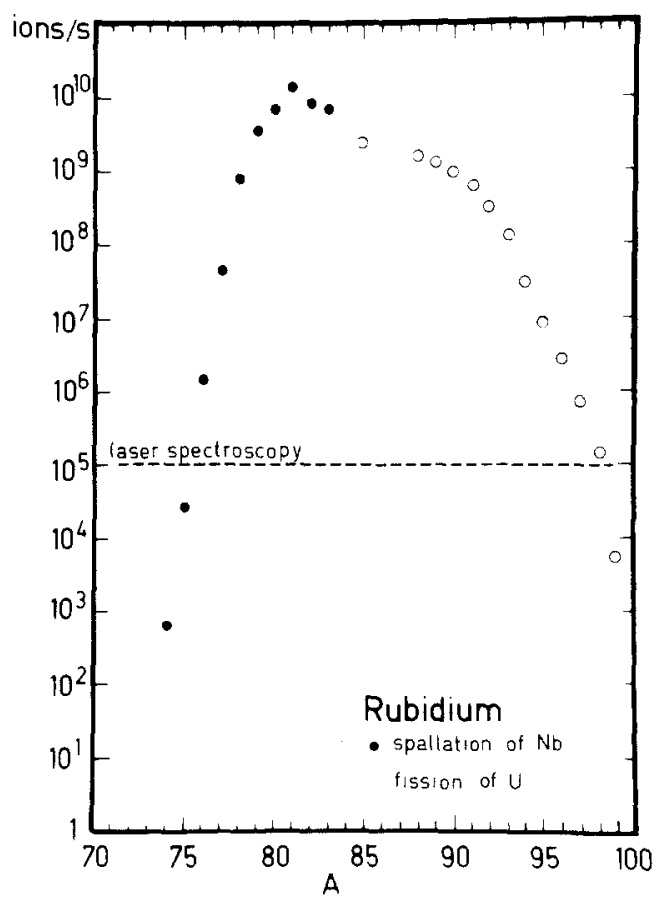

Fig. 2. Available yields of $\mathrm{Rb}$ from ISOLDE, normalized to $1 \mu \mathrm{A}, 600 \mathrm{MeV}$ proton beam $(2-3 \mu \mathrm{A}$ are generally used). (From Ravn et al. Nucl. Instr. Meth. 123(1975)131.) 
formation on the transition from atomic properties to nuclear ones will then be given. In the last section, a brief review of the methods for mass measurements will be presented, and the two examples given will illustrate how the deformations and shell effects may be observed through the study of the variations of $M$ and $\left\langle r^{2}\right\rangle$ as functions of the neutron number.

\section{On-line spectroscopy using thermal atomic beams}

In order to perform high-resolution Doppler-free spectroscopy, the isotopes to be studied are produced as a thermal atomic beam which interacts at right angles with the light from a tunable $\mathrm{cw}$ dye laser. The observation of the resonances is based on the magnetic detection of optical pumpings.

\subsection{PRODUCTION OF THE THERMAL ATOMIC BEAM}

When the experiment is directly on-line with the P.S., the target [1] is built in such a way that the alkali isotopes diffuse out in some $10 \mathrm{~ms}$ and are emitted as thermal atoms.

In the case where the experiment is receiving the $60 \mathrm{keV}$ radioactive ionic beams from ISOLDE, a special device [1] has been built in which the ions are stopped and then re-emitted as thermal atoms.

In both cases, the thermal atoms are obtained with a good efficiency $(>10 \%)$, but the unavoidable collimation leads to a transmission of $\sim 10^{-4}$. Indeed, the detection must be very efficient in order to keep a sensitivity compatible with the available yields.

\subsection{PRINCIPLE OF DETECTION OF THE RESONANCES}

The ground-state level of the alkalies is $S_{1 / 2}$. The first excited levels are the fine structure doublet $\mathrm{P}_{1 / 2}-\mathrm{P}_{3 / 2}$. The hyperfine structures of the $\mathrm{S}_{1 / 2}$ and $\mathrm{P}_{1 / 2}$ levels have two components $F=I \pm 1 / 2$ (except for $I=0$ ), the separation of which depends on $I$ and $\mu$ through the hyperfine constant $A$. The $\mathrm{P}_{3 / 2}$ level has four hyperfine sublevels $F=I-3 / 2, \ldots, F=I+3 / 2$ if $I \geqslant 3 / 2$. Their spacings depend on $I, \mu$, and $Q_{5}$. Of course, we studied the $S_{1 / 2}-P_{3 / 2}$ transitions ( $D_{2}$ lines) wherever possible in order to obtain the $Q_{\mathrm{s}}$ values also.

Figure 3(a) shows a typical case of the $\mathrm{D}_{2}$ line corresponding to $I=3 / 2$. For the sake of simplicity, this example will be used throughout this paper. Six transitions may be induced by the laser light (selection rule $\Delta F=0, \pm 1$ ). Four of them (denoted $\mathrm{a}, \mathrm{b}, \mathrm{e}, \mathrm{f}$ ) will induce a hyperfine optical pumping since the subsequent de-excitation is allowed for both the ground-state sublevels. The other two transitions (denoted c, d) may only induce a Zeeman pumping if $\sigma$ polarized light is used in the presence of a 


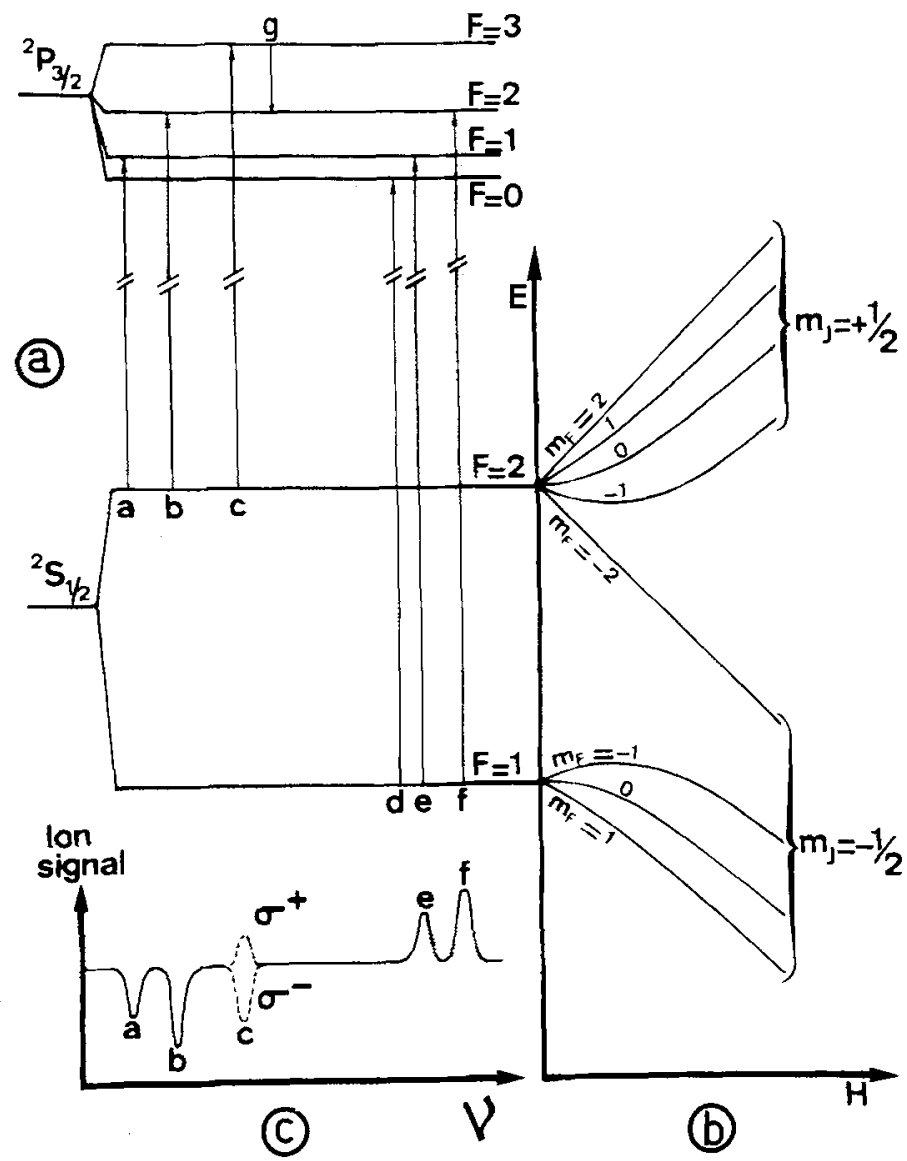

Fig. 3. (a) Level scheme of the $\mathrm{D}_{2}$ line for $I=3 / 2$. (b) Evolution of the ground-state sublevels in an increasing magnetic field $H$. (c) Signals observed by scanning the light frequency.

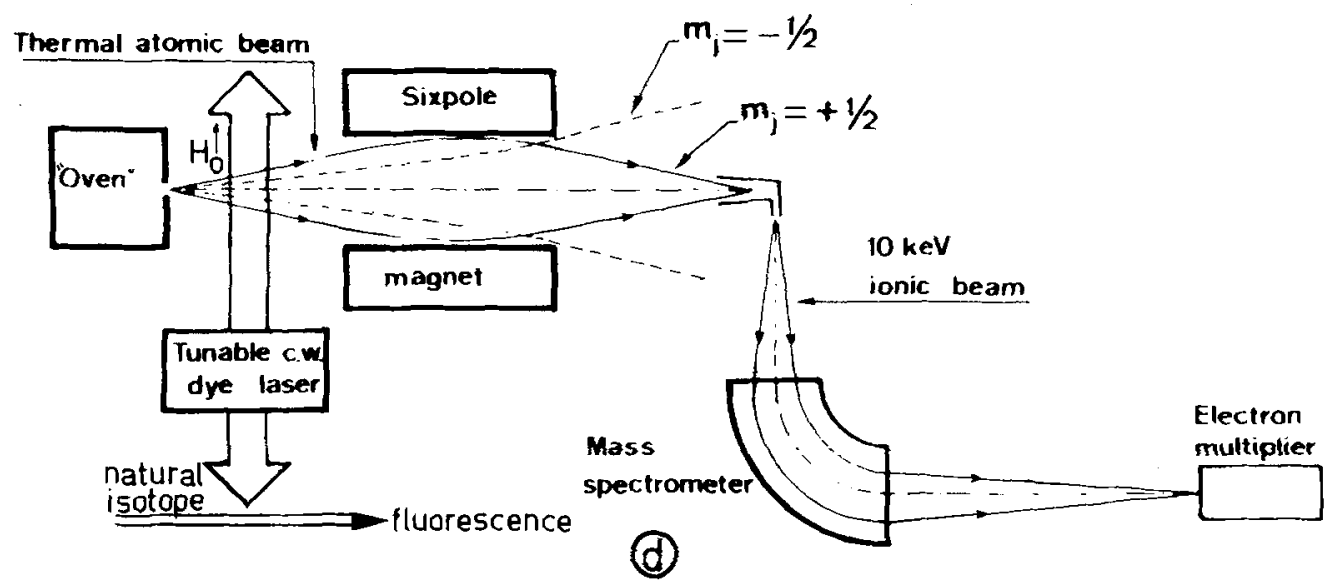

Fig. 3. (d) Scheme of the experimental set-up. The so-called 'oven' is either the target itself, or a device which transforms the $60 \mathrm{keV}$ ions into thermal atoms. 


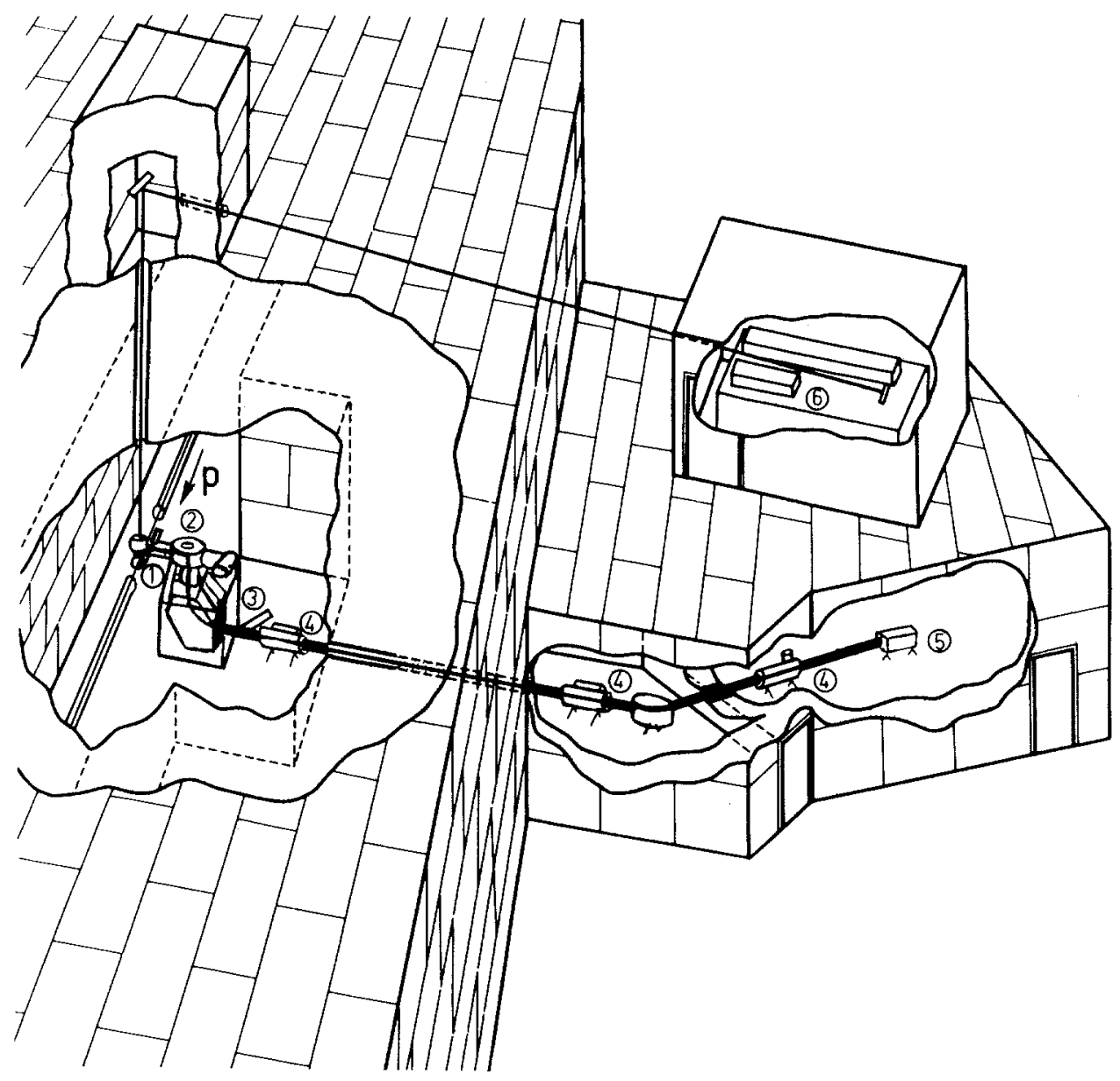

Fig. 4. General layout of the P.S. experiment. (1) Target for laser spectroscopy, interaction with the laser light, six-pole magnet. (2) Ionizer (or target plus ionizer for mass measurements), acceleration voltage. (3) Mass spectrometer. (4) Ionic beam transport through the shielding. (5) Electron multiplier. (6) Lasers.

small magnetic field $H_{0}$ parallel to the light-propagation axis $\left(\Delta m_{\mathrm{F}}=+1\right.$ for $\sigma^{+}$, $\Delta m_{\mathrm{F}}=-1$ for $\sigma^{-}$).

The method of detection involves passing the atoms adiabatically through a strong magnetic field produced by a six-pole magnet. As shown in fig. 3(b), $I$ and $J$ will decouple and the atoms will be focused by the six-pole magnet if $m_{J}=+1 / 2$, and defocused if $m_{J}=-1 / 2$ [fig. 3(d)]. The focused atoms of the isotope studied are ionized, mass selected, and counted by an electron multiplier as a function of the wave length [fig. 3(c)]. This detection has an efficiency better than $50 \%$. The general layout of the P.S. experiment [2] is represented in fig. 4. 
As shown in fig. 3(c), the transitions a and b which depopulate the $F=2$ sublevel will give rise to negative signals, while the transitions e and $\mathrm{f}$ will produce positive signals when the laser wave length is scanned.

In the case of the $c$ transition, a $\sigma^{-}$light will populate the $m_{\mathrm{F}}=-2$ sublevel and thus induce a negative signal, while a $\sigma^{+}$polarization will induce a positive signal. This change makes for easy identification.

The $d$ transition may not be observed since the three Zeeman sublevels of the $F=1$ hyperfine level are all defocused, but it would have given redundant information.

As an example, the signals obtained for ${ }^{93} \mathrm{Rb}$ are shown in fig. 5. The line width is $\sim 40 \mathrm{MHz}$. The precision of the hyperfine constants $A$ and $B$ is $\sim 1 \mathrm{MHz}$.

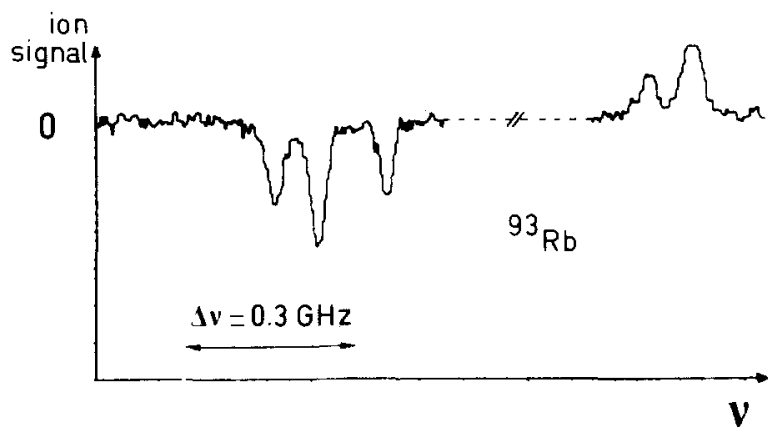

Fig. 5. Recording of the components of the $\mathrm{D}_{2}$ line of ${ }^{93} \mathrm{Rb}$.

The isotope shifts (IS) are measured by comparing the positions of the resonances with those of a reference natural isotope produced in an auxiliary beam [see fig. 4(d)]. Figure 6 shows the relative positions of the $\mathrm{D}_{1}$ lines of $\mathrm{Na}$ isotopes using ${ }^{23} \mathrm{Na}$ as a reference. The $\mathrm{D}_{1}$ lines have only four components, which all give rise to hyperfine pumping as $a, b, e, f$.

\subsection{DOUBLE RESONANCE MEASUREMENTS}

The line width of $40 \mathrm{MHz}$ allows a good resolution of the $\mathrm{D}_{2}$ line for $\mathrm{Rb}, \mathrm{Cs}$ and Fr. For the cases of $\mathrm{Na}$ [e.g. ${ }^{21} \mathrm{Na}$, fig. 7(a)] and $\mathrm{K}$, however, the hyperfine constant $B$ could not be accurately determined $(\sim 3 \mathrm{MHz})$ or even determined at all.

A double resonance - laser plus if excitations -- has been used to improve the accuracy of $B$. The laser frequency is locked on the $c$ transition with $\sigma^{+}$polarization: a small positive signal is observed. Since there is no hyperfine pumping, the atoms may undergo a large number of excitations and de-excitations during the interaction time. It is thus possible to induce a transition by $\mathrm{rf}$ excitation while the atom is in the excited state [g transition in fig. 3(a)]. The total cycle is then $(I=3 / 2)$ : 


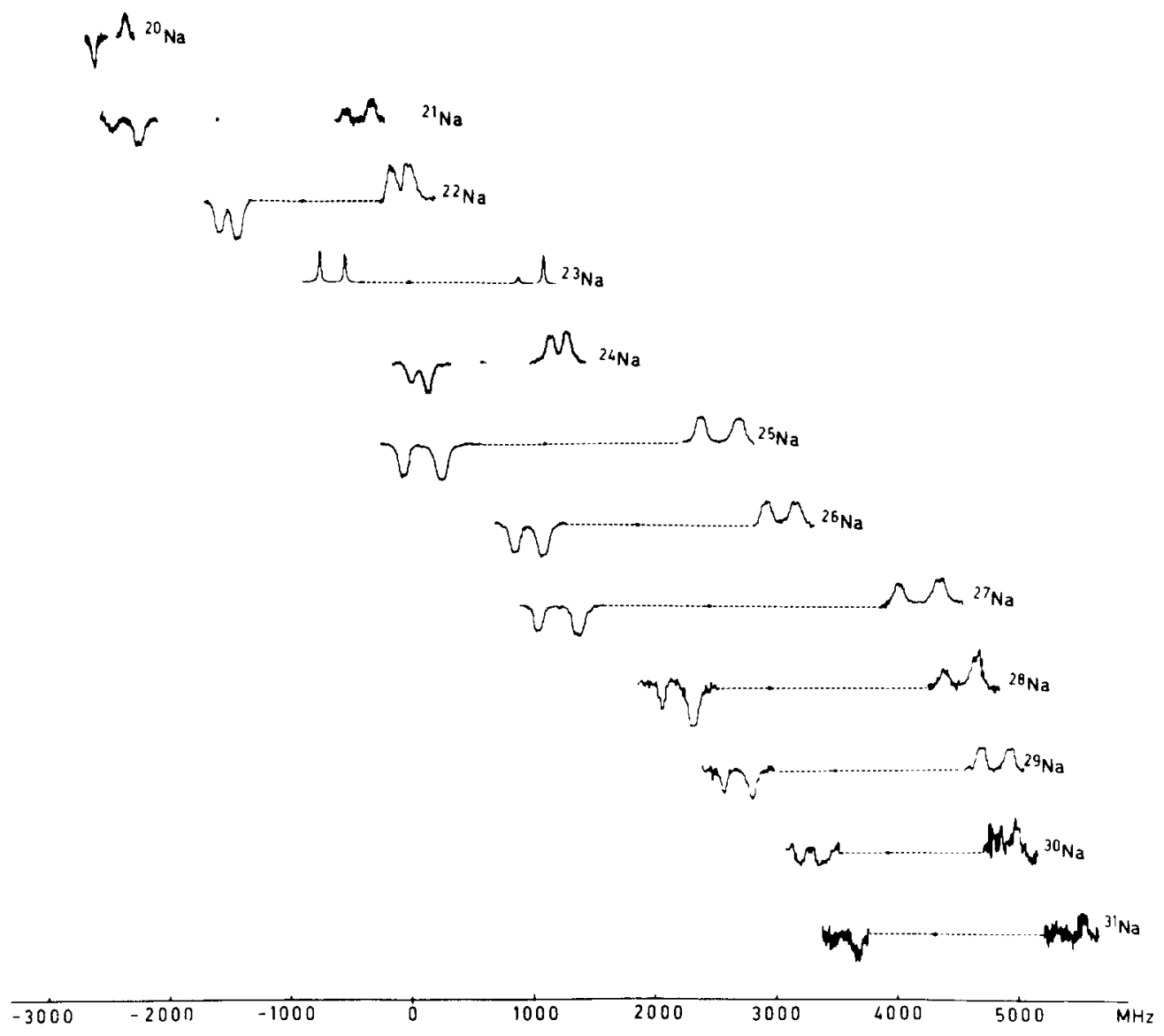

Fig. 6. Hyperfine structure and isotope shifts of the $D_{1}$ line of sodium. The resonances of ${ }^{23} \mathrm{Na}$ which serve as reference are observed by fluorescence. 

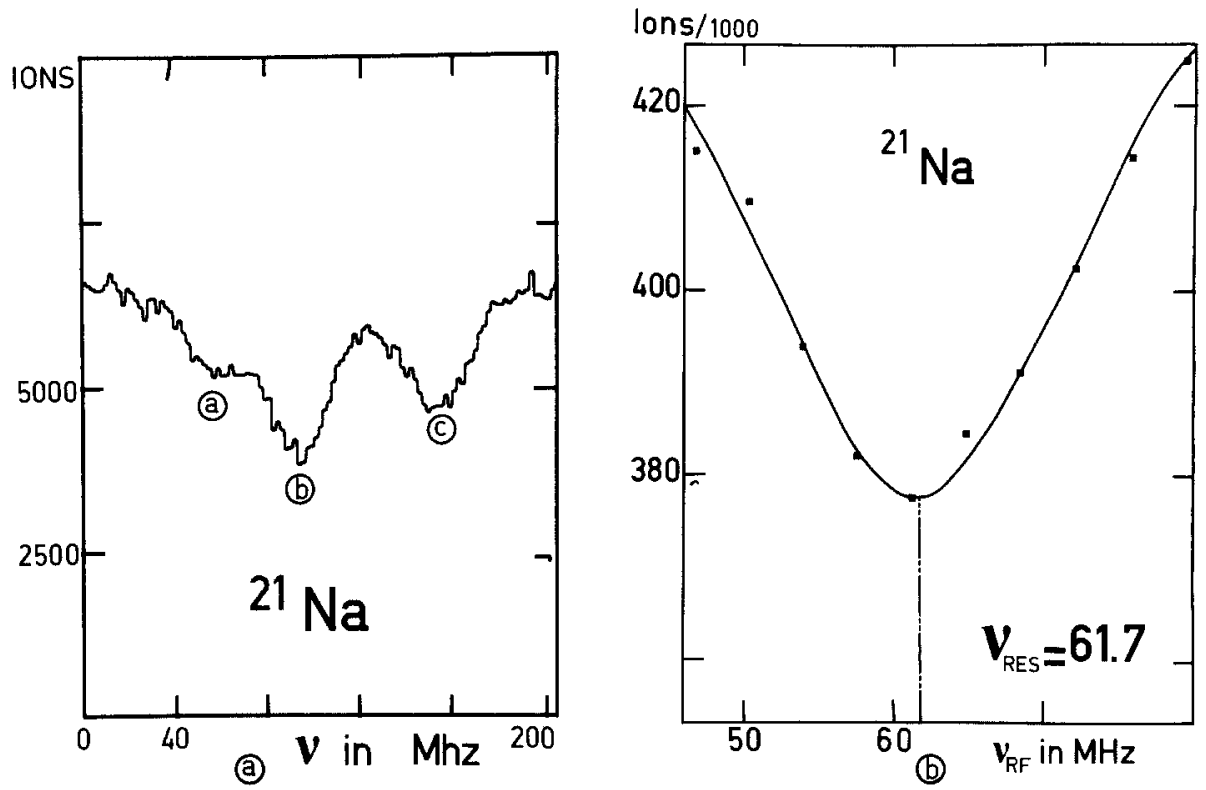

Fig. 7. (a) Negative components of the $D_{2}$ line of ${ }^{21} \mathrm{Na}$ as obtained by laser spectroscopy. (b) Measurement of the separation between the components $b$ and $c$ by double resonance for ${ }^{21} \mathrm{Na}$.

$$
\mathrm{S}_{1 / 2}, F=2 \underset{\sigma^{+}}{\stackrel{\text { laser }}{\longrightarrow}} \mathrm{P}_{3 / 2}, F=3 \stackrel{\mathrm{rf}}{\rightarrow} \mathrm{P}_{3 / 2}, F=2<\begin{aligned}
& \mathrm{S}_{1 / 2}, F=2 \\
& \mathrm{~S}_{1 / 2}, F=1
\end{aligned}
$$

and a hyperfine pumping occurs which depopulates the $\mathrm{P}_{3 / 2} F=2$ level and creates a negative signal instead of the positive one [fig. 7(b)].

Such measurements could be performed on ${ }^{21,25-29} \mathrm{Na}$, giving an accuracy of $\sim 1 \mathrm{MHz}$ for $B$ after taking into account the influence of a possible mistuning of the laser frequency.

\subsection{RADIO FREQUENCY MEASUREMENT OF THE HYPERFINE STRUCTURE OF THE GROUND STATE}

In some cases, even the ground-state sublevels are not well separated (e.g. ${ }^{20} \mathrm{Na}$ in fig. 6). In order to determine them accurately, a combination of laser and rf excitations has been used. The atoms are first excited by the laser light so that hyperfine pumping is produced (e.g. $\mathrm{b}$ transition in fig. 3(a), which produces a negative signal). Now, if the atoms are excited by an rf field tuned on the transition between the two hyperfine sublevels of the ground state, the effect of the optical pumping will be 
destroyed and the observed signal will vanish. Since there is no natural width, the different lines corresponding to the different Zeeman sublevels are resolved and the accuracy is a few $\mathrm{kHz}$. This method has been used for ${ }^{20} \mathrm{Na}$ and ${ }^{43,44,45} \mathrm{~K}$.

\subsection{SPIN DETERMINATION}

When unknown, the spin may also be measured in these experiments by combining laser and rf excitations: if the laser is tuned with $\sigma^{-}$polarization on the $\mathrm{c}$ transition [fig. 3(a)], only Zeeman pumping is induced and a negative signal is produced since the $m_{\mathrm{F}}=-2$ level is preferentially populated. If a radio frequency is added which induces transitions between neighbouring Zeeman sublevels, it will tend to re-equalize their populations and cancel the signal. The resonance frequency $\nu_{\mathrm{rf}}$, the static field $H_{0}$, and the spin $I$ are related by

$$
\nu_{\mathrm{rf}}(2 I+1) / H_{0}=\text { Cte }
$$

After calibration with a known spin, one has just to scan discrete values of $H_{0}$ corresponding to the different possible values of $I(1,2,3$, or $1 / 2,3 / 2, \ldots)$ and determine for which one the negative signal is lowered.

In the case of the $D_{1}$ line, it is also possible to use the e or $f$ transitions with $\sigma$ polarized light, since they populate unequally the different Zeeman sublevels of $F=2$, of which not all are focused. However, the change in the signal is weaker.

\subsection{CONCLUSIONS}

Table 1 summarizes the results obtained up to now and the corresponding references. Hopefully, more results will be obtained during 1984 to complete the study of $\mathrm{Rb}, \mathrm{Cs}$, and $\mathrm{Fr}$.

\section{The case of francium}

The francium element is a very special case. The isotope ${ }^{223} \mathrm{Fr}$ which appears in a weak branch of the decay of ${ }^{235} \mathrm{U}$ was discovered in 1939 [11]. Although its half-life is the longest among the Fr isotopes, it is still short so that 1 ton of natural $\mathrm{U}$ contains only $6 \cdot 10^{-12} \mathrm{~g}$ of ${ }^{223} \mathrm{Fr}$. Indeed, it was totally hopeless to search for an optical resonance in natural francium. Nowadays, ISOLDE can provide a $10^{8}$ ions/s beam of ${ }^{223} \mathrm{Fr}$, produced in the spallation of $\mathrm{U}$ or Th by the $600 \mathrm{MeV}$ proton beam from the S.C. This is quite suitable for laser spectroscopy.

However, another problem arose when looking at the predictions of the wave length (fig. 8). The range to scan is very wide - of the order of $100 \mathrm{~nm} \sim 5 \cdot 10^{7} \mathrm{MHz}-$ 
Table 1

Alkali isotopes for which we have measured hyperfine structures (h.f.s.) and isotope shifts (IS)

\begin{tabular}{lccc}
\hline & \multicolumn{2}{c}{ Mass numbers } & \\
\cline { 2 - 3 } Element & $\begin{array}{c}\text { h.f.s. } \mathrm{D}_{2} \\
\text { and IS }\end{array}$ & $\begin{array}{c}\text { h.f.s. } \mathrm{D}_{1} \\
\text { and IS }\end{array}$ & Refs. \\
\hline${ }_{11} \mathrm{Na}$ & $21,25-29$ & $20-31$ & {$[3,4]$} \\
${ }_{19} \mathrm{~K}$ & $76-98$ & {$[5,6]$} \\
${ }_{37} \mathrm{Rb}$ & $78 \mathrm{~m}, 81 \mathrm{~m}, 82 \mathrm{~m}$ & {$[7]$} \\
& $84 \mathrm{~m}, 86 \mathrm{~m}, 90 \mathrm{~m}$ & \\
${ }_{55} \mathrm{Cs}$ & $118-145$ & & {$[8,9]$} \\
& $119 \mathrm{~m}, 121 \mathrm{~m}, 122 \mathrm{~m}$ & {$[10]$} \\
${ }_{87} \mathrm{Fr}$ & $130 \mathrm{~m}, 134 \mathrm{~m}, 135 \mathrm{~m}$ & & \\
\hline
\end{tabular}

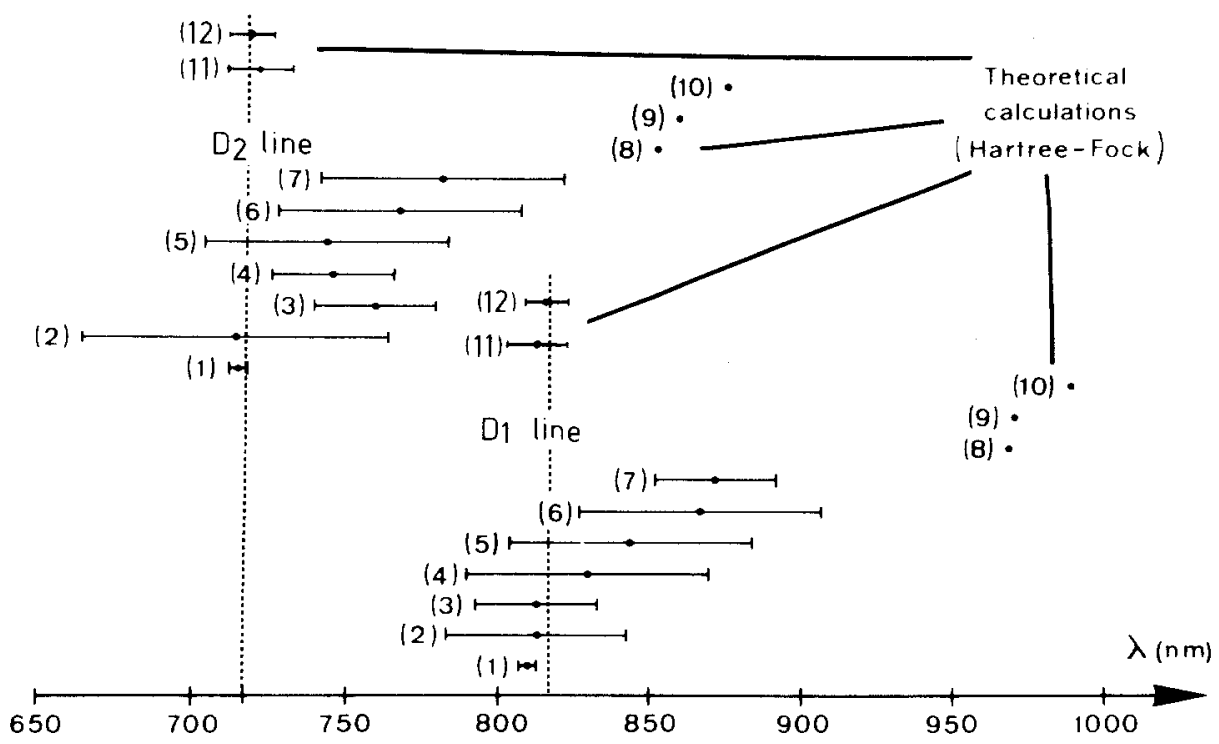

Fig. 8. Theoretical and semi-empirical predictions of the wave lengths of $D_{1}$ and $D_{2}$ Fr lines with their estimated uncertainty bars. The dashed lines indicate our experimental determinations. (1) See ref. [13], (2)-(10) see ref. [10] and references therein, (11) see ref. [14], (12) see ref. [15]. 
when compared with the line width of $40 \mathrm{MHz}$. A reasonable estimate for such an exploration on-line with an accelerator is $1-2$ days. This has been performed by using a multimode laser which gave five packets of modes, thus multiplying by five the range really scanned. Furthermore, the laser light has been spread to enlarge the line width by Doppler effect and to make it compatible with the $300 \mathrm{MHz}$ width of each mode packet. This device enabled us to discover the $D_{2}$ line in 1978 $(\lambda=717.97 \pm 0.01 \mathrm{~nm})[10,12]$.

An improved device consisting of a cw dye laser synchronously pumped by a mode-locked $\mathrm{Kr}^{+}$laser enabled us to find the $\mathrm{D}_{1}$ line in December 1983 $(\lambda=816.90 \pm 0.02 \mathrm{~nm})$.

The positions of the lines (fig. 8) are in very good agreement with the old prediction by Yagoda [13] (1932), while many extrapolations resulted in too large values of the wave lengths. Nevertheless, the value of the fine structure was generally rather well predicted. More recently, two ab initio calculations using the HartreeSlater method and taking into account the relativistic effects have been developed. The first one is due to Lundberg and Rosen [14], while the second has been performed by Dzuba et al. [15] subsequent to the measurement of the $D_{2}$ wave length. Both calculations are in excellent agreement with our measurements (fig. 8) and predict $\lambda=433 \mathrm{~nm}$ and $\lambda=423 \mathrm{~nm}$, respectively, for the transitions $7 \mathrm{~S}_{1 / 2}-8 \mathrm{P}_{1 / 2}$ and $7 \mathrm{~S}_{1 / 2}-8 \mathrm{P}_{3 / 2}$. A search for these two lines is planned in the near future.

\section{Relations between atomic and nuclear properties}

4.1. ZEEMAN SPLITTING

As already mentioned, the Zeeman splitting $\nu_{\mathrm{rf}}$ is related to the spin $I$ by

$$
v_{\mathrm{rf}}(2 I+1) / H_{0}=\mathrm{Cte} .
$$

\subsection{HYPERFINE STRUCTURE,}

The relative energies of the different sublevels are given by

$$
W(I, J, F)=A \frac{C}{2}+B \frac{3 / 2 C(C+1)-2 I(I+1) J(J+1)}{2 I(2 I-1) 2 J(2 J-1)} .
$$

where $C=F(F+1)-I(I+1)-J(J+1)$.

(i) $A$ is related to $\mu$ and $I$ by:

$\mu / I A=-J / H_{\mathrm{e}}$, where $H_{\mathrm{e}}$ is the magnetic field at the center of the nucleus which depends only on $Z$ if the hyperfine anomaly is neglected. 
In the case of alkali elements, $\mu$ is known for at least one isotope used as reference (for Fr, see ref. [16]) so that the other magnetic moments are simply obtained through the relation

$$
\mu=\mu_{\text {ref }} I A / I_{\text {ref }} A_{\text {ref }} .
$$

(ii) $B$ depends on $Q_{\mathrm{s}}$ :

$B / e Q_{\mathrm{s}}=\phi_{J J}(0)$, where $\phi_{J J}(0)$ is the mean value of the electric field gradient at the center of the nucleus in the direction of $J$. $\phi_{J J}$ has been evaluated by using the Hartree -Slater calculations made by Rosen and Lindgren [17], with shielding corrections as given by Sternheimer and Peierls [18]. The absolute values are thus modeldependent, but not the relative ones.

However, the nuclear models generally need the value of the intrinsic moment $Q$ rather than that of its projection $Q_{\mathrm{s}}$. But $Q$ and $Q_{5}$ are simply related only in the case of nuclei with a large static deformation where

$$
Q_{\mathrm{s}}=Q I(2 I-1) /[(I+1)(2 I+3)] .
$$

Anyway, the interpretation of the values of $Q_{\mathrm{s}}$ is model-dependent and sometimes hazardous.

\subsection{ISOTOPE SHIFTS}

The isotope shift has two different origins:

(i) The one which concerns the nuclear physicist is the volume (or field) shift which takes into account the fact that the nucleus has a non-zero mean square charge radius $\left\langle r^{2}\right\rangle$ which varies from one isotope to the next one:

$$
\Delta \nu_{\mathrm{vol}}=F(Z) \delta\left\langle r^{2}\right\rangle
$$

where $F(Z)$ may be estimated theoretically as proposed by Heilig and Steude1 [19]. The variation of $\left\langle r^{2}\right\rangle$ is sensitive to the changes in the shape of the nuclei. It may be expressed as a sum of two terms:

$$
\delta\left\langle r^{2}\right\rangle=\delta_{\mathrm{sph}}\left\langle r^{2}\right\rangle+\delta_{\beta}\left\langle r^{2}\right\rangle
$$

where $\delta_{\mathrm{sph}}\left\langle r^{2}\right\rangle$ is the variation of $\left\langle r^{2}\right\rangle$ when adding neutrons in spherical nuclei. An evaluation of this term may be obtained from the liquid drop models [20]. $\delta_{\beta}\left\langle r^{2}\right\rangle$ 
reflects the departure from the spherical shape. It increases with the deformation. In the case of a quadrupole static deformation at constant volume, it may be expressed as

$$
\delta_{\beta}\left\langle r^{2}\right\rangle=\frac{5}{4 \pi} \delta\left(\left\langle r^{2}\right\rangle_{\mathrm{sph}}\left\langle\beta^{2}\right\rangle\right) .
$$

(ii) The other term is due to the change of mass along the series of isotopes:

$$
\Delta \nu_{\text {mass }}=K \Delta\left(\frac{1}{M}\right)=\left(K_{\mathrm{n}}+K_{\mathrm{s}}\right) \Delta\left(\frac{1}{M}\right) .
$$

The constant $K$ is the sum of two terms:

- The normal (Bohr) effect which depends only on the interaction between the nucleus and the electrons considered as independent. This is easy to calculate:

$$
K_{\mathrm{n}}=v m_{\mathrm{e}}
$$

where $m_{\mathrm{e}}$ is the electron mass.

- The specific mass effect which takes into account the interaction between the electrons cannot be calculated with enough accuracy. However, in the case of potassium and rubidium elements where two natural isotopes exist, a calibration may be obtained from muonic X-ray measurements (see the paper by R.M. Steffen in this volume) which provides

$$
K_{\mathrm{s}}=-0.06 K_{\mathrm{n}} \text { for } \mathrm{K}
$$

and

$$
K_{\mathrm{s}}=-0.03 K_{\mathrm{n}} \quad \text { for } \mathrm{Rb} .
$$

In other cases, one has to speculate. But it should be noticed that while the volume effect is largely preponderant for heavy elements, the reverse situation is met in the light elements: for Cs which is heavy, the assumption that $K_{\mathrm{s}}=0$ as in $\mathrm{Ba}$ is certainly not false and has a negligible influence on the evaluation of $\delta\left\langle r^{2}\right\rangle$. For Na which is very light, the situation is extremely difficult. As a first approximation, one may neglect $\Delta \nu_{\text {vol }}$ so that

$$
K \simeq \Delta \nu / \Delta\left(\frac{1}{M}\right)=380 \text { to } 388 \mathrm{GHz} \times \mathrm{amu} .
$$


The $8 \mathrm{GHz} \times$ amu fluctuations correspond to the volume effect. An intermediate value has to be chosen. This may be done by fitting the experimental results on Hartree-Fock calculations [21] for ${ }^{23-27} \mathrm{Na}$, or by assuming that ${ }^{25} \mathrm{Na}$ and ${ }^{27} \mathrm{Na}$ (spin $I=5 / 2$ ) are spherical. One or the other of these assumptions leads us to adopt $K=385.5 \mathrm{GHz} \times$ amu, corresponding to a large specific effect

$$
K_{\mathrm{s}}=+0.38 K_{\mathrm{n}} .
$$

Nevertheless, a modification of the value of $K$ will rotate the whole curve $\delta\left\langle r^{2}\right\rangle=f(N)$ around its reference point $\left({ }^{25} \mathrm{Na}\right)$ but will not crucially change the relative radii of the different isotopes.

\section{Mass determinations}

\subsection{WHY?}

The mass of the nucleus is directly connected to its binding energy and accordingly is a very fundamental quantity.

Mass measurements will allow us:

- to study shell effects and pairing energies,

- to test the nucleon-nucleon effective interactions used in Hartree-Fock calculations,

- to test the shell model which could be developed up to $Z=20$ [22],

- to test long-range extrapolations using semi-empirical mass formulae [23 25] which are needed in the calculations of nucleosynthesis of the elements.

Mass measurements will also be helpful in the preparation of other experiments in order to predict unusual decay modes such as $t$ or $\alpha \beta$-delayed emission, or to predict $Q$ values for heavy ion transfer reactions.

\subsection{WHAT ACCURACY?}

Whatever the goal of mass measurements is, an absolute accuracy of $100 \mathrm{keV}$ is needed. This corresponds to a relative accuracy of $10^{-5}$ for $A=10$, and $10^{-6}$ for $A=100$.

\subsection{HOW?}

One way to avoid the difficulties in the high-accuracy measurements is by measuring mass differences, i.e. decay energies $\left(\alpha, \beta^{-}, \beta^{+}\right.$, p-decays) or $Q$ of two-body 
nuclear reactions $\left(M_{1}+M_{2} \rightarrow M_{3}+M_{4}+Q\right)$. The order of magnitude of these differences is around $10 \mathrm{MeV}$, so that the needed accuracy is only $\sim 10^{-2}$.

Alternatively, one must face the difficulties associated with the high-accuracy measurements. The presently available methods aim at determining mass ratios through

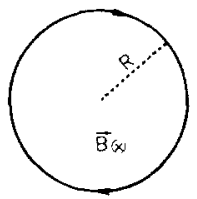

$f=q B / 2+M$

(a)

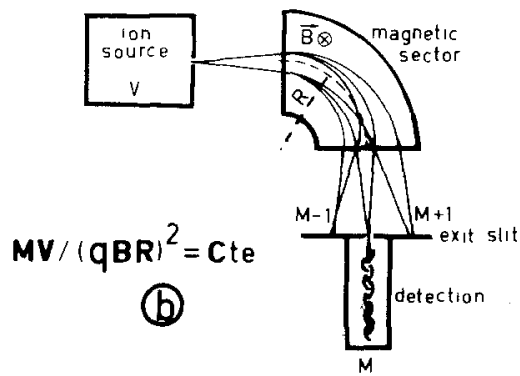

(b)

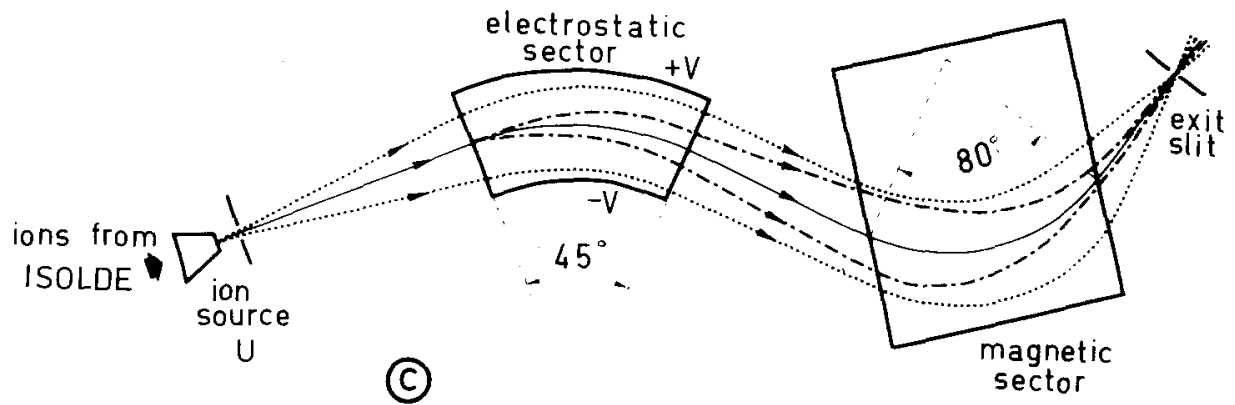

Fig. 9. Principle of the measurement of mass ratios using the properties of ions rotating in a magnetic field $B$. (a) The ions rotate with frequency $f$, (b) a magnetic sector is used: single-stage mass spectrometer, (c) double focusing (energy and angular spread) mass spectrometer.

the measurement of frequency or voltage ratios. They use the properties of ions rotating in a constant magnetic field $B$ (fig. 9):

(i) The frequency of rotation $f$, or 'cyclotron frequency', is related to the mass $M$ of the ion and to its charge $q$ by

$$
f=q B / 2 \pi M,
$$

so that $M_{1} / M_{2}=f_{2} / f_{1}$ if $B$ is constant.

The cyclotron frequencies may be measured by radio frequency mass spectrometers such as the one we are building, or by ion traps. Such facilities have not yet been used for exotic nuclei, but will be operational in a few years at ISOLDE 3 at CERN. 
(ii) By using a magnetic sector, one may determine the values of the potentials $V_{1}$ and $V_{2}$ for which the ions of masses $M_{1}$ and $M_{2}$ follow the same trajectory while $B$ is kept constant. Then

$$
M_{1} / M_{2}=V_{2} / V_{1} .
$$

Up to now, we have used two different mass spectrometers for such measurements at CERN. The first one was a single-stage magnetic spectrometer [fig. 9(b)]. Its resolving power was 500. An accuracy of some $10^{-6}$ could be obtained for light elements, i.e. $\mathrm{Li}$ and $\mathrm{Na}$ produced at the P.S. at CERN. The same set-up as for laser spectroscopy (fig. 4) could be used: the target was removed from 1 to 2 , very near the ionizer, and the whole mass spectrometer $(1-2-3)$ was moved towards the proton beam so that the target was again in front of it.

For heavy elements produced by ISOLDE, a two-stage double-focusing mass spectrometer was used [fig. 9(c)]. Its resolving power was $\sim 20000$. The accuracy obtained was $2 \cdot 10^{-7}$ for $\mathrm{Rb}, \mathrm{Cs}$ and $\mathrm{Fr}$ isotopes.

The masses that we measured are indicated in table 2 with the corresponding references.

(iii) Another possibility which is being tested at Los Alamos is to measure masses by measuring the energy and the time-of-flight of the ions.

Table 2

Alkali isotopes for which we have measured the mass by on-line massspectrometry

\begin{tabular}{lcl}
\hline Elements & Mass numbers & Refs. \\
\hline${ }_{3} \mathrm{Li}$ & 11 & {$[26]$} \\
${ }_{11} \mathrm{Na}$ & $26-34$ & {$[26,27]$} \\
${ }_{37} \mathrm{Rb}$ & $74-79,90-99$ & {$[28,29]$} \\
& $116-124,126,138$ & \\
${ }_{55} \mathrm{Cs}$ & $140-148$ & {$[28,29,30]$} \\
${ }_{87} \mathrm{Fir}$ & $204-210,212,224-228$ & {$[31,29]$} \\
\hline
\end{tabular}

\section{Masses and radii: Discussion of $\mathrm{Rb}$ and $\mathrm{Na}$ results}

Figure 10 presents very schematically the type of information that may be obtained by mass measurements and by laser spectroscopy. We shall here focus our interest where we can obtain cross information, i.e. the observation of deformations and shell effects, and their comparison with Hartree-Fock calculations. 


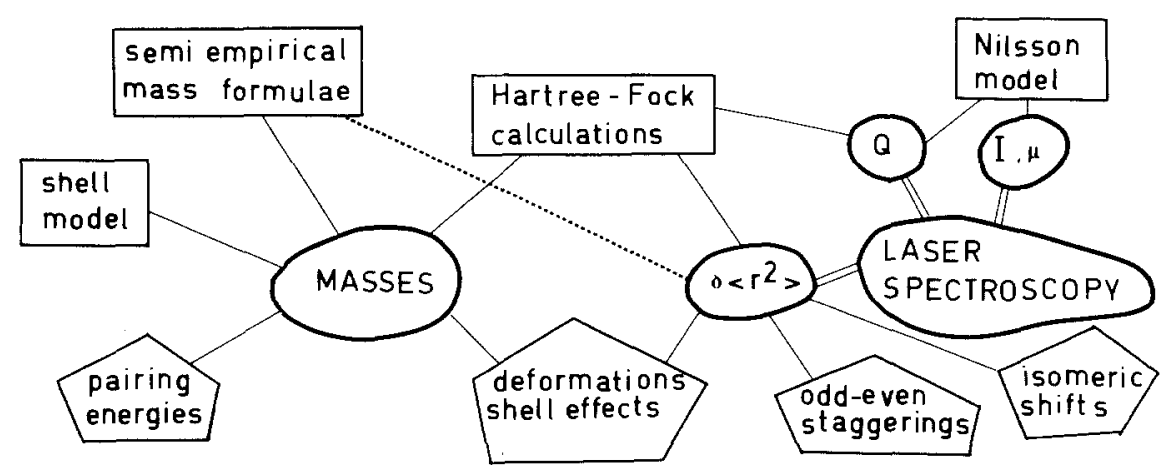

Fig. 10. Scheme of the information that can be obtained by mass measurements and by laser spectroscopy.

Since the variations of $M$ and $\left\langle r^{2}\right\rangle$ are relatively small, they will be plotted directly rather than the absolute values.

For masses, the most natural procedure would be to plot differences between neighbouring isotopes. But due to the strong pairing energies, it is better to look at the differences between isotopes of the same parity, i.e. at the two-neutron separation energies

$$
S_{2 \mathrm{n}}=M_{\mathrm{N}}-M_{\mathrm{N}-2} .
$$

For laser spectroscopy, we shall only show the variations of $\delta\left\langle r^{2}\right\rangle$ using ${ }^{87} \mathrm{Rb}$ and ${ }^{25} \mathrm{Na}$ as zero points.

\subsection{RUBIDIUM (fig. 11)}

(i) Shell closure at $N=50$. The shell closure strongly influences both masses and radii:

As expected, $S_{2 \mathrm{n}}$ drops abruptly when the neutrons start filling a new shell at $N=51$, and thus are less tightly bound.

Qualitatively, $\delta\left\langle r^{2}\right\rangle$ increases as expected when neutrons are added in the new shell. But $\delta\left\langle r^{2}\right\rangle$ decreases when neutrons are added to fill up the preceding one.

More quantitatively, the comparison with the regular increase of $\delta_{\mathrm{sph}}\left\langle r^{2}\right\rangle$ calculated according to the liquid drop model [20] shows that the deformation is minimum for $N=50$ and increases particularly fast when neutrons are removed.

(ii) Change of shape at $N=60$. When $S_{2 \mathrm{n}}$ was measured in 1978, an increase for $N=60$ was pointed out. It is very similar to the increase observed in the rare earths around $N=90$, which is known to be connected with a sudden change of shape.

This assumption has been successfully confirmed when $\delta\left\langle r^{2}\right\rangle$ has been measured [7] since a strong jump is observed for $N=60$. The same behaviour could also 


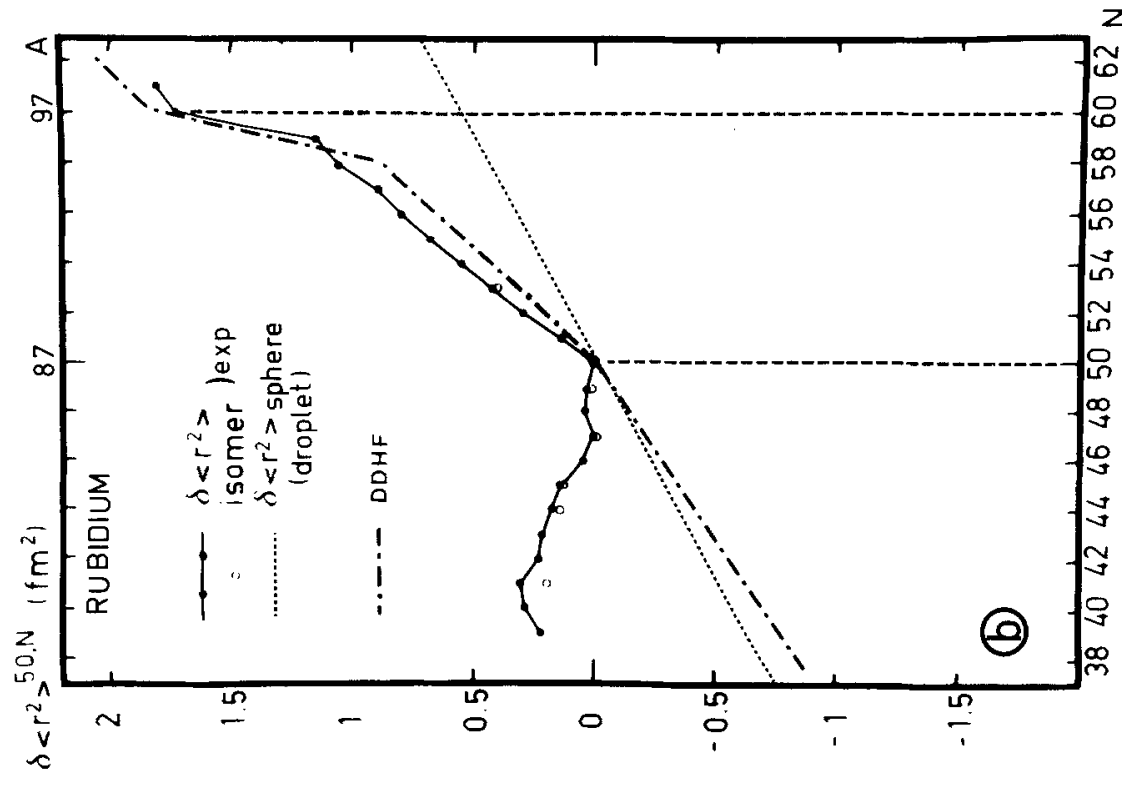

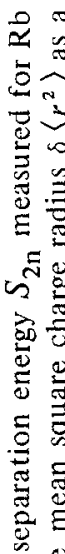

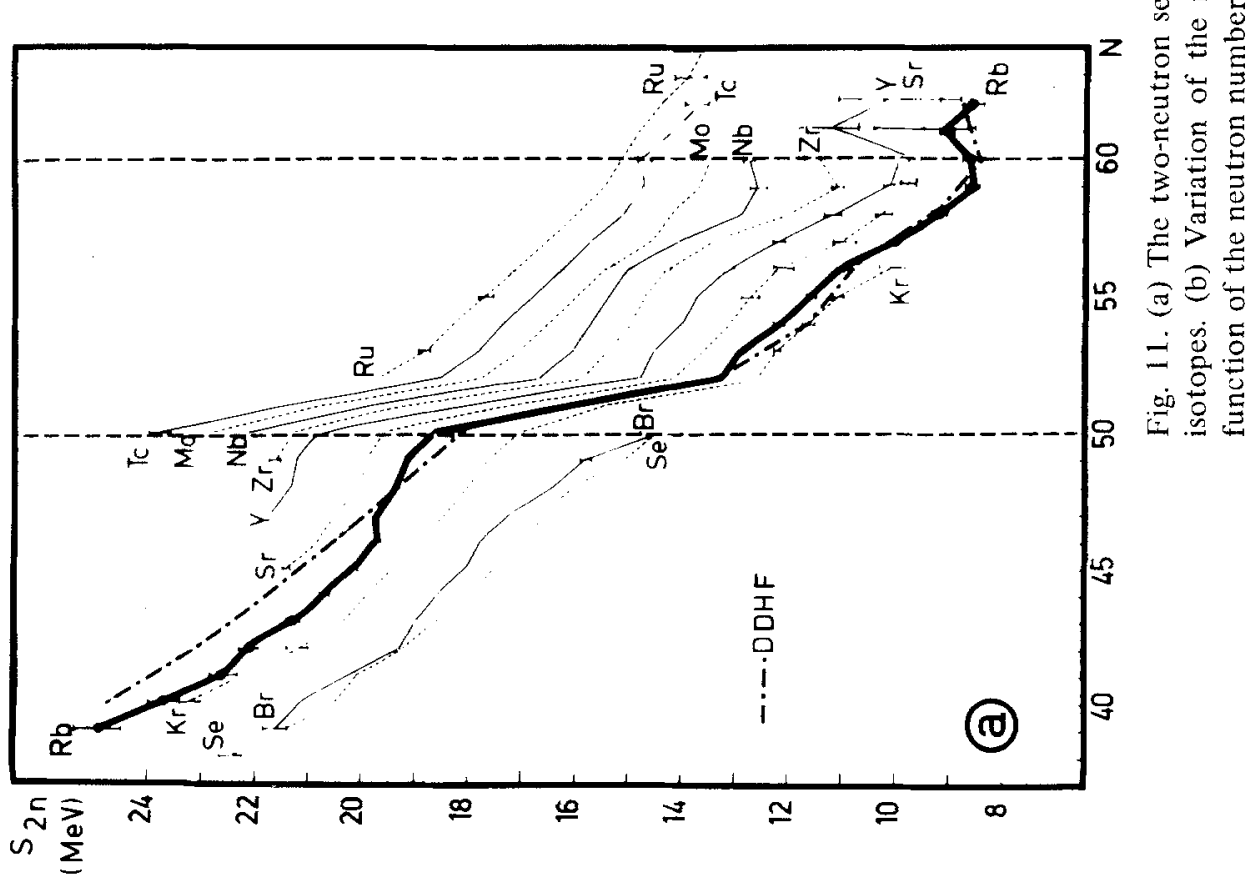


occur in the case of Cs for $N=91,92[30]$, but $\delta\left\langle r^{2}\right\rangle$ has not yet been measured for $N>90$.

(iii) Comparison with Hartree - Fock calculations. Density-dependent Hartree-Fock (DDHF) calculations using the Skyrme VI force have been performed by Campi and Epherre [32].

The effects of the change of shape are well calculated both for $S_{2 \mathrm{n}}$ and $\delta\left\langle r^{2}\right\rangle$. This change corresponds to a pure quadrupole deformation with $\beta=0.36$. This calculated value is in complete agreement with the value deduced from our measurement of $Q_{\mathrm{s}}$ [7]. Other confirmations have also been obtained, either theoretically from the Nilsson model with reproduces $I, \mu$, and $Q$ for $\beta=0.36$ [33], or experimentally from the $E_{2}+$ measurements performed on the e-e isotones ${ }^{98} \mathrm{Sr}$ [34] and ${ }^{100} \mathrm{Sr}$ [35] $(N=60,62)$.

Concerning the shell effect, $S_{2 n}$ is well reproduced but not $\delta\left\langle r^{2}\right\rangle$, since the DDHF calculations fail to find any deformation for $N<50$. However, one must keep in mind that $\delta\left\langle r^{2}\right\rangle$ depends on $\left\langle\beta^{2}\right\rangle$, while the DDHF calculations deal with $\langle\beta\rangle$ : if dynamic deformations such as zero-point vibrations occur, they will increase $\delta\left\langle r^{2}\right\rangle$, but cannot be predicted by DDHF. This could explain the misfit observed for $N=44-50$, where the nuclei are known to be vibrational [32]. But the case of the most $\mathrm{n}$-deficient isotopes is far less obvious and would have to be studied again.

\subsection{SODIUM (fig. 12)}

As expected, a clear shell effect is observed at $N=20$ for $S_{2 n}$ in the case of $\mathrm{Ca}$ and $\mathrm{K}$. But, for lighter elements it is washed out. Finally, for $\mathrm{Na}$ [26] and $\mathrm{Mg}$ [37], an increase is observed instead, which suggests a change of shape. Such an assumption is also supported by the very low first $2+$ level of ${ }^{32} \mathrm{Mg}(N=20)$ [38] .

DDHF calculations were performed for $\mathrm{Na}$ using Skyrme III [21]. A change of shape was found at $N=20$ and $S_{2 n}$ was reproduced nicely (fig. 12). The DDHF calculations could also predict the magnitude of the jump of $\delta\left\langle r^{2}\right\rangle$ expected at $N=20$.

However, our measurements do not exhibit any special jump at $N=20$. Instead, a very fast increase is observed starting from $N=17$. This could be due to vibrations of these nuclei so that the effect of the change of shape could be masked.

This example shows that perhaps mass measurements indicate a deformation which is not observable through $\delta\left\langle r^{2}\right\rangle$ measurements.

An interesting confirmation could be brought about by $Q$ measurements. Unfortunately, as explained before, the measurements are particularly difficult in the case of sodium, and therefore they have not yet been performed for $N>18$. 

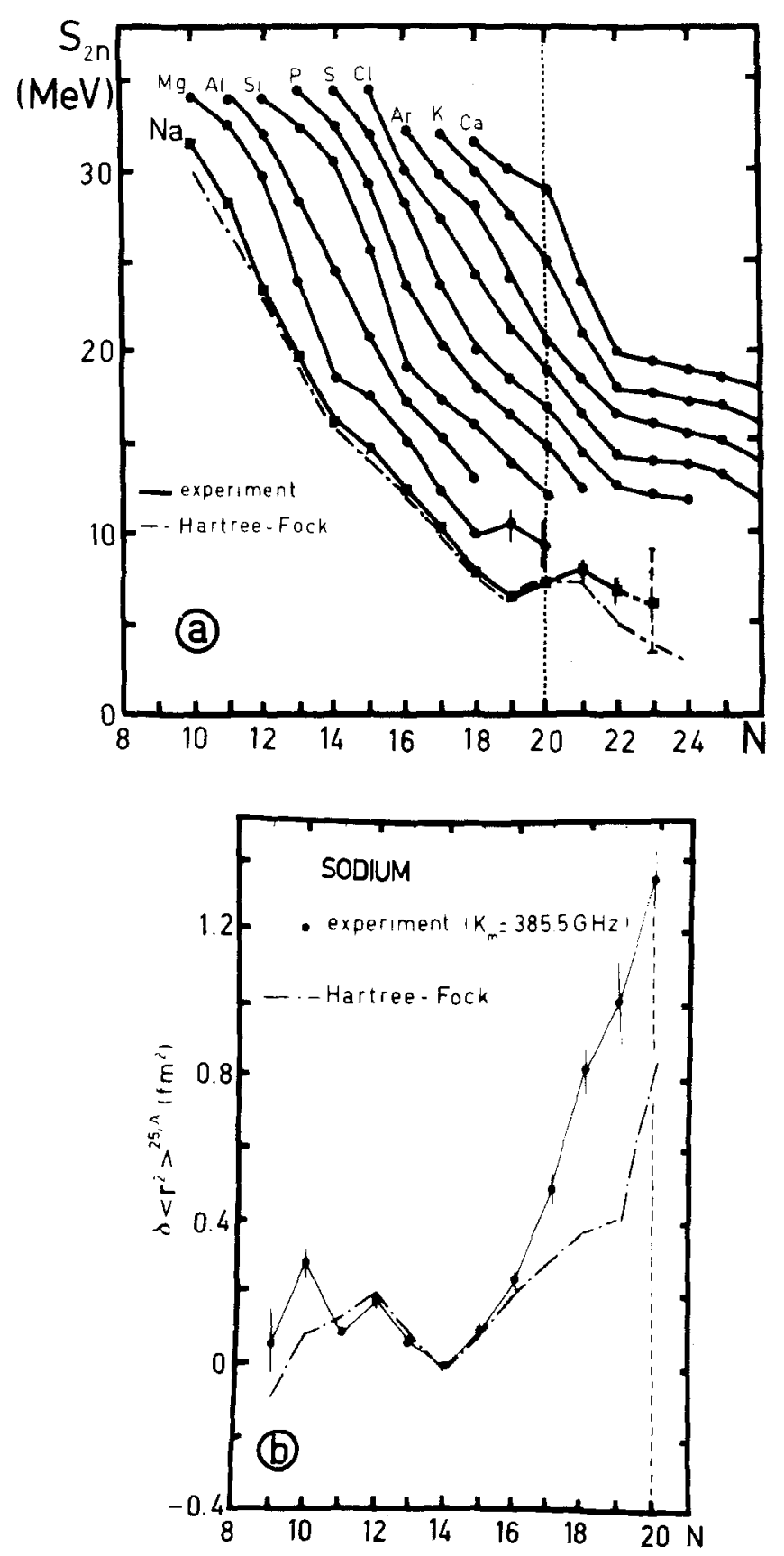

Fig. 12. (a) The two-neutron separation energy $S_{2 n}$ measured for $\mathrm{Na}$ isotopes. (b) Variation of the mean square charge radius $\delta\left\langle r^{2}\right\rangle$ with the neutron number. 


\section{Conclusions}

The combination of laser spectroscopy and mass measurements allowed us to study the evolution of the ground-state properties of the alkali isotopes as a function of the neutron number. As shown in the two examples of $\mathrm{Na}$ and $\mathrm{Rb}$, it is particularly interesting to compare the results with the predictions of models which calculate both masses and radii.

\section{Acknowledgements}

I would like to acknowledge the help from many coworkers who worked so hard on these experiments: G. Audi, N. Bendali, S. Büttgenbach, A. Coc, H.T. Duong, M. Epherre, P. Guimbal, G. Huber, P. Jacquinot, P. Juncar, R. Klapisch, L. Lessard, S. Liberman, A. Pesnelle, P. Pillet, J. Pinard, A.M. Poskanzer, R. Prieels, W. Reisdorf, C. Rigaud, M. de Saint Simon, J.M. Saint Jalm, J.M. Serre, F. Touchard, J.L. Vialle and $\mathrm{H}$. Wollnik. My thanks also go to the excellent technical staff whose contribution was essential for the accomplishment of the present work, and they include: J. Baronnet, J. Biderman, R. Fergeau, M. Jacotin, J.F. Képinski, G. Le Scornet, C. Vialle, the ISOLDE collaboration, and the S.C. and P.S. staff.

\section{References}

[1] F. Touchard, J. Biderman, M. de Saint Simon, C. Thibault, G. Huber, M. Epherre and R. Klapisch, Nucl. Instr. Meth. 186(1981)329.

[2] M. de Saint Simon, R. Fergeau, M. Jacotin, J.F. Képinski, R. Klapisch, C. Thibault, F. Touchard, M. Langevin and D. Guillemaud, Nucl. Instr. Meth. 186(1981)87.

[3] G. Huber, F. Touchard, S. Büttgenbach, C. Thibault, R. Klapisch, H.T. Duong, S. Liberman, J. Pinard, J.L. Vialle, P. Juncar and P. Jacquinot, Phys. Rev. C18(1978) 2342.

[4] F. Touchard, J.M. Serre, S. Büttgenbach, P. Guimbal, R. Klapisch, M. de Saint Simon, C. Thibault, H.T. Duong, P. Juncar, S. Liberman, J. Pinard and J.L. Vialle, Phys. Rev. C25 (1982)2756.

[5] F. Touchard, P. Guimbal, S. Büttgenbach, R. Klapisch, M. de Saint Simon, J.M. Serre, C. Thibault, H.T. Duong, P. Juncar, S. Liberman, J. Pinard and J.L. Vialle, Phys. Lett. 108B(1982)169.

[6] H.T. Duong, P. Juncar, S. Liberman, J. Pinard, J.L. Vialle, S. Büttgenbach, P. Guimbal, M. de Saint Simon, J.M. Serre, C. Thibault, F. Touchard and R. Klapisch, J. de Phys. 43 (1982)509.

[7] C. Thibault, F. Touchard, S. Büttgenbach, R. Klapisch, M. de Saint Simon, H.T. Duong, P. Jacquinot, P. Juncar, S. Liberman, P. Pillet, J. Pinard, J.L. Vialle, A. Pesnelle and G. Huber, Phys. Rev. C23(1981)2720.

[8] G. Huber, F. Touchard, S. Büttgenbach, C. Thibault, R. Klapisch, S. Liberman, J. Pinard, H.T. Duong, P. Juncar, J.L. Vialle, P. Jacquinot and A. Pesnelle, Phys. Rev. Lett. 41(1978) 459. 
[9] C. Thibault, F. Touchard, S. Büttgenbach, R. Klapisch, M. de Saint Simon, H.T. Duong, P. Jacquinot, P. Juncar, S. Liberman, P. Pillet, J. Pinard, J.L. Vialle, A. Pesnelle, the ISOLDE Collaboration and G. Huber, Nucl. Phys. A367(1981)1.

[10] S. Liberman, J. Pinard, H.T. Duong, P. Juncar, P. Pillet, J.L. Vialle, P. Jacquinot, F. Touchard, S. Büttgenbach, C. Thibault, M. de Saint Simon, R. Klapisch, A. Pesnelle, the ISOLDE Collaboration and G. Huber, Phys. Rev. A22(1980)2732.

[11] M. Perey, C.R. Acad. Sci. Paris 208(1939)97.

[12] S. Liberman, J. Pinard, H.T. Duong, P. Juncar, J.L. Vialle, P. Jacquinot, G. Huber, I. Touchard, S. Büttgenbach, A. Pesnelle, C. Thibault and R. Klapisch, C.R. Acad. Sci. Paris B286(1978)253.

[13] H. Yagoda, Phys. Rev. 40(1932)1017.

[14] H. Lundberg and A. Rosen, Z. Phys. A286(1978)329.

[15] V.A. Dzuba, V.V. Flambaum and O.P. Sushkov, Phys. Lett. 95A(1983)230.

[16] C. Ekström, Atomic Physics 8, Göteborg 1980, Abstract B44.

[17] A. Rosen and I. Lindgren, Phys. Scripta 6(1972)109.

[18] R.M. Sternheimer and R.F. Peierls, Phys. Rev. A3(1971)837.

[19]. K. Heilig and A. Steudel, At. Data and Nucl. Data Tables 14(1974)613.

[20] W.D. Myers and K.H. Schmidt, Nucl. Phys. A410(1983)61, and references therein.

[21] X. Campi, H. Flocard, A.K. Kerman and S. Koonin, Nucl. Phys. A251(1975)193.

[22] A. Watt, R.P. Singhal, M.H. Storm and R.R. Whitehead, J. Phys. G7(1981)L145.

[23] At. Data and Nucl. Data Tables 17(1976)411.

[24] P. Möller and J.R. Nix, Nucl. Phys. A361(1981)117; At. Data and Nucl. Data Tables 26 (1981)165.

[25] M. Uno and M. Yamada, Progr. Theor. Phys. 65(1981)1322; Report INS-NUMA-40 (1982).

[26] C. Thibault, R. Klapisch, C. Rigaud, A.M. Poskanzer, R. Pricels, L. Lessard and W. Reisdorf, Phys. Rev. C12(1975)644.

[27] C. Thibault, M. Epherre, G. Audi, R. Klapisch, G. Huber, F. Touchard, D. Guillemaud and F. Naulin, Proc. Sixth Int. Conf. on Atomic Masses, East Lansing, Michigan, 1979, ed. J.A. Nolen, Jr. and W. Benenson (Plenum, New York-London, 1980) p. 291.

[28] M. Epherre, G. Audi, C. Thibault, R. Klapisch, G. Huber, F. Touchard, H. Wollnik and the ISOLDE Collaboration, Phys. Rev. C19(1979)1504.

[29] G. Audi, M. Epherre, C. Thibault, A.H. Wapstra and K. Bos, Nucl. Phys. A378(1982)443.

[30] G. Audi, A. Coc, M. Epherre, G. Le Scornet, C. Thibault, F. Touchard and ISOLDE Collaboration, to be submitted to Nucl. Phys. A.

[31] M. Epherre, G. Audi, C. Thibault, R. Klapisch, G. Huber, F. Touchard and H. Wollnik, Nucl. Phys. A340(1980)1.

[32] X. Campi and M. Epherre, Phys. Rev. C22(1980)2605.

[33] I. Ragnarsson, Proc. Int. Symp. on Future Directions in Studies of Nuclei far from Stability, Nashville, Tennessee, 1979, ed. J.H. Hamilton, E.H. Spejewski, C.R. Bingham and E.T. Zganjar (North-Holland, Amsterdam, 1980) p. 367.

[34] H. Wollnik, F.K. Wohm, K.D. Wünsch and C. Jüng, Nucl. Phys. A291(1977)355.

[35] R.E. Azuma, G.L. Borchert, L.C. Carraz, P.G. Hansen, B. Jonson, S. Mattson, O.B. Nielsen, G. Nyman, I. Ragnarsson and H.L. Ravn, Phys. Lett. 86B(1979)5.

[36] C. Ekström, Proc. 4th Int. Conf. on Nuclei far from Stability, Helsingør, 1981, ed. P.G. Hansen and O.B. Nielsen, CERN Report (CERN 81-09, Geneve, 1981) p. 12.

137] C. Detraz, M. Langevin, M.C. Goffri-Kouassi, D. Guillemaud, M. Epherre, G. Audi, C. Thibault and F. Touchard, Nucl. Phys. A394(1983)378.

[38] D. Guillemaud-Mueller, C. Detraz, M. Langevin, I. Naulin, M. de Saint Simon, C. Thibault. F. Touchard and M. Epherre, Nucl. Phys. A, to be published. 


\section{Discussion}

R. Neugart: Your Na results indicate a minimum of deformation for ${ }^{25} \mathrm{Na}$. How can this be explained in terms of the neutron shell structure?

C. Thibault: It is known that a subshell effect may occur for $N=14$. The masses do not exhibit such an effect, but the values of $\delta\left\langle r^{2}\right\rangle$ and of the quadrupoie moment both indicate it. It is also found both by Hartree-Fock calculations and by the liquid drop mass formula, e.g. from Möller and Nix (ref. [24] in the text).

R. Neugart: I am referring to the Hartree-Fock calculations for Rb. You ascribe the discrepancies for the neutron-deficient isotopes to the vibrational structure which is not included in the calculations. On the other hand, the lightest isotopes should be quite strongly deformed. Do the theorists have any idea as to why this is not reproduced by the calculation?

C. Thibault: $\quad$ I agree with your remark but I do not know the answer. I must try to get in touch with the theoreticians and ask them if they really checked carefully if the very $\mathrm{n}$-deficient $\mathrm{Rb}$ isotopes could be deformed.

R.E. Silverans: Concerning the laser-RF spectroscopy work, you quote an accuracy of a few $\mathrm{kHz}$; did you take into account the possible occurrence of light shifts if the laser is slightly detuned from resonance?

C. Thibault: In the case of ground-state hyperfine structure measurements, the accuracy is around a few $\mathrm{kHz}$, as you mention. There is no influence from a mistuning of the laser since the laser and the radio frequency excitations are not acting in the same spot; first laser and then radio frequency. In the case of the double resonance (h.f.s. of the excited level), the accuracy is around $1 \mathrm{MHz}$ including the influence of a possible mistuning of the laser wave length. This effect has been calibrated by using an intense beam of natural sodium ${ }^{23} \mathrm{Na}$ where the h.f.s. is accurately known. In both cases, one has to also take into account the Zeeman splitting of the levels, but this correction may be calculated with negligible uncertainty.

H.J. Kluge: When you did the experiments on $\mathrm{Rb}$ and $\mathrm{Cs}$ masses, some experimental data on short-lived isotopes obtained by $Q$ measurements already existed. Did you find these data to be correct?

C. Thibault: $\quad$ Many masses of $\mathrm{Rb}$ and $\mathrm{Cs}$ have been determined by measuring the energy spectrum of the $\beta^{-}$or $\beta^{+}$emitted in coincidence with selected $\gamma$-ray lines. However, it may occur that a level higher than the one expected is fed, resulting in an estimation of $Q_{\beta}$ which is too low. So, there were many discrepancies with our results when we published them. A careful check of the decay schemes has allowed the correction of all $Q$ results for $\mathrm{Rb}$. In the case of neutron-deficient Cs, I think that one or two cases are still in disagreement.

R. Coussement: You did not discuss the residual interactions used in Hartree-Fock calculations. Probably the agreement will depend on the residual interaction used. 
C. Thibault: In the density-dependent Hartree-Fock calculations which have been shown, an effective nucleon-nucleon interaction has been used (Skyrme III or IV if I remember correctly). These calculations are not time dependent and can only deal with static deformations. They have no way to find if the nuclei should be vibrating. Up to now, it seems that the main disagreement occurs for vibrational nuclei.

H.A. Schuessler: Could you describe your apparatus which was used for magnetic and electrostatic deflection? What was the limiting factor for your resolution of 10000 ?

C. Thibault: $\quad$ Our apparatus was a double focusing (angular plus energy dispersion) device with a Mattauch-Herzog geometry (see Phys. Rev. C19(1979)1504 for details on the apparatus and on the method. A resolution of 40000 at best could be obtained. It is limited by the second-order aberration. One must also note that in order to increase the resolution, one has to close the entrance and exit slits so that the transmission decreases accordingly. The best compromise, from the point of view of the accuracy, was generally for a resolution around $5000-10000$ (slit apertures $10-15 \mu$ ).

\section{Note added in proof}

1. The measurement of the wave length of the $D_{1}$ line of francium has been published: N. Bendali, H.T. Duong, P. Juncar, S. Liberman, J. Pinard, J.M. Saint Jalm, J.L. Vialle, S. Büttgenbach, C. Thibault, F. Touchard, A. Pesnelle, A.C. Mueller and the ISOLDE Collaboration, C.R. Acad. Sci. Paris 299(1984)1157.

2. We have now performed new measurements on francium: (i) the blue lines have been observed: see the Proceedings of AMCO 7, ed. O. Klepper (Technische Hochschule Darmstadt Lehrdruckerei) p. 353. (ii) The spin, hyperfine structures and isotope shifts of ${ }^{220-228} \mathrm{Fr}$ have been measured, indicating the occurrence of octupolar deformations as for the radium isotones (A. Coc et al., submitted to Phys. Lett.).

3. New Hartree-Fock calculations have been performed for the neutrondeficient $\mathrm{Kr}$ and Sr isotopes: P. Bonche et al., Rep. IPNO-TH 85/12 Orsay. 